\section{Theoretical \& Applied Science}

p-ISSN: 2308-4944 (print) e-ISSN: 2409-0085 (online)

Year: $2015 \quad$ Issue: $01 \quad$ Volume: 21

Published: $30.01 .2015 \quad$ http://www.T-Science.org student,

Moscow State University of economics, statistics and informatics, Russia

katerina392781@rambler.ru

Natalia Igorevna Reshetko associate professor,

Moscow State University of economics, statistics and informatics, Russia

Natalia.Reshetko@,rambler.ru

SECTION 31. Economic research, finance, innovation, risk management.

\title{
CONSTRUCTION OF THE GRADING SYSTEM AS AN EXAMPLE OF QWELL GROUP
}

Abstract: The article describes a method of job evaluation as described in the company HayGroup, on the basis of which the meshing of grades, as well as plug wages. he object of investigation was chosen outsourcing company $q$ Well Group and conducted an analysis of the wage system and after the introduction of grading grid

Key words: grade, job evaluation, job title, salary fork.

Language: Russian

Citation: Bogunec EA, Reshetko NI (2015) CONSTRUCTION OF THE GRADING SYSTEM AS AN EXAMPLE OF QWELL GROUP. ISJ Theoretical \& Applied Science 01 (21): 156-163. doi: http://dx.doi.org/10.15863/TAS.2015.01.21.27

\section{ПОСТРОЕНИЕ СИСТЕМЫ ГРЕЙДОВ НА ПРИМЕРЕ КОМПАНИИ QWЕLL GROUР}

Аннотация: B статье описана методика оценки должностей по методике компании НауGroup, на основе которой осуществляется построение сетки грейдов, а также вилки заработных плат. В качестве объекта исследования была выбрана аутсорсинговая компания qWell Group и проведен анализ имеющейся системы оплаты труда и после внедрения сетки грейдов.

Ключевые слова: грейд, оценка должности, должность, вилка заработных плат.

\begin{abstract}
Одним из вопросов современной экономики стал аспект человеческого потенциала, анализ имеющихся трудовых ресурсов, их возможности и пути их использования в конкретной компании. На сегодняшний момент - это один из аспектов изучения менеджмента, который подразумевает управление такими ресурсами, работы с ними. Человек - это такой же экономический ресурс, который имеет свои возможности реализации.

Осознание того, что люди - это ключевой ресурс организации, способный поднять её на «звездную высоту» успеха или низвергнуть в пучину поражений, с каждым днем все прочнее укрепляется в нашем сознании. Поэтому многие руководители, желая, чтобы их персонал стал прочной опорой и поддержкой организации, стремятся К использованию современных инструментов HR-политики. В задачи кадровой политики каждой компании входит не просто обеспечение необходимым персоналом, но и оценка качества персонала, а именно обеспечение высокого уровня квалификации
\end{abstract}

работников для повышения эффективности работы компании и достижения максимальной результативности.

Методика построения системы грейдов сегодня довольна распространена, поэтому исследование методологии оценки должностей является актуальным, особенно в российской практике. Основной целью данной работы является исследование метода оценки должностей на основе рекомендаций компании HayGroup, которая является передовой в разработке данной системы и методологии.

Современная бизнес-среда подвержена динамичному развитию рынка, поэтому требует оперативной адаптации на малейшие изменения среды. Результатом такой адаптации может стать смена организационной структуры, разработка новой технологии ведения бизнеса, что приводит к появлению новых профессий и должностей, а также к смене функционала и роли уже имеющейся базы профессий.

Как известно, каждый человек по своей сути индивидуален, хоть ему и присущи общие 
для всех людей черты - именно поэтому одно из важнейших правил оценки является то, что специалист обязан оценивать должность, а не человека, который ее занимает. Неверное распределение человеческих ресурсов поднимает вопрос эффективности бизнеса, его рентабельности и развития. Именно поэтому оценка должностей на основе методики компании Хэй Груп приобрела огромную популярность в деловой среде.

Методика оценки должностей компании HayGroup является наиболее распространенной и признанной в бизнес среде. HayGroup консалтинговая компания, специализирующая в сфере управления персоналом, была основана в 1945 году в Филадельфии. Методику оценки должностей разработал Эдвард Хэй в 1940 году, использовав в качестве основы факторную систему оценки должностей. Опубликован метод был только в 1962 году после смерти его разработчика, а авторские права перешли к самой компании.

Оценка должностей - определение ценности должности для организации при помощи методологии, которая основана на шкале оценки и единых критериях. Также ее можно определить, как процесс измерения веса должности при помощи четких единых критериев. Главной целью оценки должностей является исключение субъективности в оценке. Оценка должна основываться на анализе должностных инструкций сотрудников (может быть дополнена опросом «360 градусов»).

Ключевыми характеристиками методики оценки должностей HayGroup являются:

1. это метод измерения относительной важности или должности;

2. метод оценки степени, в которой должность влияет на достижение целей компании;

3. объективный и универсальный подход;

4. позволяет использовать универсальный язык общения при обсуждении должности между руководителями;

5. не математический метод оценки;

6. определяет относительные ценности компании (квалификация, ответственность и т.д.);

7. оценка достигается в процессе обсуждения (это коллективный труд).

Широкое применение методики обуславливает ее преимущества:

- при построении линейной организационной структуры компании сталкиваются с проблемой уравнения должности с ее положением в структуре организации, исключая факт функционального влияния на результат деятельности;

- оценка должностей позволяет более точно сравнить должность работника с рынком, а также привнести индивидуальность в построении структуры должностей организации;

- позволяет реализовать принцип справедливости посредством единства критериев оценки для всех уровней иерархии должностей, а также ясно сопоставить уровень вознаграждения для каждой должности;

- единые критерии позволяют внести ясность в стратегические цели и вклад каждой должности в результат ее достижения, чтобы избежать дублирования;

- позволяет

пересматривать организационную структуру предприятия с учетом процессов, ролей и областей ответственности;

- позволяет соотнести оценку должностей c построением модели компетенции в компании.

Оценка должностей согласно методике компании HayGroup включает в себя 3 группы факторов, каждая из которых определяется несколькими параметрами оценки:

- знания и умения Know How;

- решение вопросов Problem Solving;

- ответственность Responsibility.

Соотношение показателей позволяет оценить должность как совокупность параметров в рамках одной группы и выразить эту оценку в количественном показателе как размер факторов в виде суммы хэй-поинтов. При каждом сочетании параметров указан его тип - логичное, маловероятное и нелогичное, что позволяет корректировать оценку должности в каждой группе факторов при каждом сочетании параметров.

Результатом оценки является величина должности, выраженная в сумме хэй-поинтов, что определяет еe положение в иерархии системы грейдов.

Компания QWell Group - консалтинговая компания, которая представляет сферу услуг в различных областях. Компания была образована в 2007 году путем реинжиниринга уже существовавших бизнесов. Компания известна своими аутсорсинговыми и маркетинговыми проектами.

Ключевыми направлениями деятельности являются:

- Management - включает в себя несколько обособленных проектов: 
аутсорсинг бухгалтерских услуг, аутсорсинг юридических услуг, аутсорсинг HR услуг, аутсорсинг ИТ услуг;

- Marketing - полный цикл маркетинговых услуг;

- Region - полный спектр услуг в 36 регионах России, причем каждое подразделение является самостоятельным и уполномочено самостоятельно решать вопросы в рамках политики компании и предоставляемых услуг;
- Staffing - аутсорсинг и предоставление временного персонала.

Клиентами QWell Group являются такие известные компании как

AШAH, OBI, METRO, GLOBUS, IKEA, REAL, SELGROSS, LEROY MERLIN, BILLA и другие.

Первым шагом на пути к построению системы грейдов является оценка должностей, для которой необходимо штатное расписание компании и описание должности, т.е. должностная инструкция.

\section{Структура должностей в компании QWell Group Region СПб}

Таблица 1

\begin{tabular}{|c|c|c|c|c|}
\hline \multicolumn{2}{|c|}{ Структурное подразделение } & \multirow[b]{2}{*}{ Должность } & \multirow{2}{*}{$\begin{array}{c}\text { Количество } \\
\text { штатных } \\
\text { единиц }\end{array}$} & \multirow[b]{2}{*}{$\begin{array}{l}\text { Тарифная } \\
\text { ставка }\end{array}$} \\
\hline $\begin{array}{l}\text { Наименование } \\
\text { отдела }\end{array}$ & Код & & & \\
\hline \multirow{3}{*}{ Административный } & 01 & Заместитель руководителя ОП & 1 & 200000 \\
\hline & 01 & Технический специалист & 1 & 30000 \\
\hline & 01 & Директор регионального управления & 1 & 275000 \\
\hline \multirow{2}{*}{$\begin{array}{l}\text { Отдел обучения и } \\
\text { контроля }\end{array}$} & 01 & $\begin{array}{l}\text { Старший менеджер по обучению и } \\
\text { контролю }\end{array}$ & 1 & 45000 \\
\hline & 02 & Менеджер по обучению и контролю & 2 & 25000 \\
\hline \multirow{3}{*}{$\begin{array}{l}\text { Отдел по работе с } \\
\text { заказчиками }\end{array}$} & 03 & менеджер по работе с заказчиками & 8 & 23000 \\
\hline & 03 & Оператор базы данных & 6 & 20000 \\
\hline & 03 & $\begin{array}{l}\text { Старший менеджер по работе с } \\
\text { заказчиками }\end{array}$ & 3 & 42500 \\
\hline \multirow{4}{*}{$\begin{array}{l}\text { Отдел подбора } \\
\text { персонала }\end{array}$} & 04 & Менеджер по подбору персонала & 2 & 40000 \\
\hline & 04 & $\begin{array}{cccc}\text { Старший } & \text { менеджер } & \text { по } & \text { подбору } \\
\text { персонала }\end{array}$ & 1 & 47000 \\
\hline & 04 & $\begin{array}{llll}\begin{array}{l}\text { Менеджер } \\
\text { (стажер) }\end{array} & \text { по подбору } & \text { персонала } \\
\end{array}$ & 1 & 17000 \\
\hline & 04 & $\begin{array}{l}\text { Руководитель } \\
\text { персонала }\end{array}$ & 1 & 70000 \\
\hline \multirow{2}{*}{$\begin{array}{l}\text { Отдел поддержки } \\
\text { бизнеса }\end{array}$} & 05 & Специалист по поддержке бизнеса & 2 & 25000 \\
\hline & 05 & $\begin{array}{l}\text { Старший специалист по поддержке } \\
\text { бизнеса }\end{array}$ & 1 & 32000 \\
\hline \multirow{5}{*}{$\begin{array}{l}\text { Отдел реализации } \\
\text { проектов }\end{array}$} & 06 & $\begin{array}{l}\text { Менеджер по реализации проектов } \\
\text { (стажер) }\end{array}$ & 3 & 17000 \\
\hline & & $\begin{array}{l}\text { Менеджер по реализации проектов } \\
\text { (стажер) }\end{array}$ & 2 & 19500 \\
\hline & 06 & Менеджер по реализации проектов & 11 & 22000 \\
\hline & 06 & $\begin{array}{l}\text { Руководитель } \\
\text { проектов }\end{array}$ & 1 & 130000 \\
\hline & 06 & $\begin{array}{cccc}\text { Старший } \\
\text { проектов }\end{array}$ & 4 & 50000 \\
\hline \multirow{2}{*}{$\begin{array}{l}\text { Отдел финансового } \\
\text { контроля }\end{array}$} & 07 & Специалист по финансовому контролю & 2 & 35000 \\
\hline & 08 & $\begin{array}{l}\begin{array}{l}\text { Руководитель } \\
\text { контроля }\end{array} \\
\end{array}$ & 1 & 150000 \\
\hline Итого & & & 55 & 1315000 \\
\hline
\end{tabular}


Распределение должностей в иерархии в каждом отделе компании происходит одинаково - это прослеживается также в названиях должностей. Детализированная оценка каждой должности (с получение короткого и длинного профиля) представлена ниже:

Таблица 2

Оценка должностей компании QWell Group Region СПб согласно методике компании НауGroup.

\begin{tabular}{|c|c|c|c|c|c|c|c|c|}
\hline Должность & \multicolumn{2}{|c|}{ KH } & \multicolumn{2}{|r|}{ PB } & \multicolumn{2}{|c|}{ OT } & \multirow{2}{*}{$\begin{array}{c}\text { Сумма } \\
1560\end{array}$} & \multirow{2}{*}{$\begin{array}{c}\text { Категория } \\
\text { A2 }\end{array}$} \\
\hline $\begin{array}{l}\text { Директор } \\
\text { регионального } \\
\text { управления }\end{array}$ & GIII3 & 700 & G-4 & $57 \% / 400$ & G3S & 460 & & \\
\hline $\begin{array}{l}\text { Заместитель } \\
\text { руководителя }\end{array}$ & FIII3 & 528 & $\mathrm{~F}+4$ & $57 \% / 350$ & F3S & 304 & 1182 & $\mathrm{~A} 1$ \\
\hline $\begin{array}{lr}\text { Руководитель } & \text { отдела } \\
\text { по } & \text { реализации } \\
\text { проектов } & \\
\end{array}$ & F-III3 & 460 & $\mathrm{~F}-3$ & $50 \% / 230$ & F3S & 304 & 994 & A 2 \\
\hline $\begin{array}{l}\text { Руководитель отдела } \\
\text { финансового контроля }\end{array}$ & FII3 & 400 & $\mathrm{~F}-4$ & $50 \% / 200$ & $E+3 S$ & 230 & 830 & A1 \\
\hline $\begin{array}{ll}\text { Руководитель } \\
\text { отдела }\end{array}$ & FII3 & 304 & $\mathrm{E}+3$ & $38 \% / 115$ & $\mathrm{E}+\mathrm{N} 4$ & 132 & 523 & A1 \\
\hline $\begin{array}{ll}\text { Ст.менеджер } & \text { по } \\
\text { подбору персонала }\end{array}$ & EII3 & 230 & E-3 & $33 \% / 76$ & ENIII & 87 & 393 & A1 \\
\hline $\begin{array}{l}\text { Cт. менеджер по } \\
\text { реализации проектов }\end{array}$ & E-II2 & 230 & D-3 & $29 \% / 50$ & $\mathrm{D}+\mathrm{NIII}$ & 66 & 346 & A2 \\
\hline $\begin{array}{l}\text { Ст. менеджер по } \\
\text { обучению и контролю }\end{array}$ & E-I3 & 200 & $\mathrm{D}+3$ & $33 \% / 66$ & E-NIII & 76 & 342 & A1 \\
\hline $\begin{array}{l}\text { Ст. менеджер по } \\
\text { работе с заказчиками }\end{array}$ & E-I3 & 200 & $\mathrm{D}+3$ & $33 \% / 66$ & D+NIII & 66 & 332 & L \\
\hline $\begin{array}{l}\text { Менеджер по подбору } \\
\text { персонала }\end{array}$ & $\mathrm{D}+\mathrm{I} 3$ & 200 & D-3 & $29 \% / 57$ & $\mathrm{D}+\mathrm{NIII}$ & 66 & 323 & A1 \\
\hline $\begin{array}{l}\text { Ст. специалист по } \\
\text { поддержке бизнеса }\end{array}$ & E-I2 & 175 & D-3 & $29 \% / 50$ & $\mathrm{D}+\mathrm{NIII}$ & 66 & 291 & $\mathrm{~A} 2$ \\
\hline $\begin{array}{l}\text { Технический } \\
\text { специалист }\end{array}$ & E-I2 & 175 & $\mathrm{D}+3$ & $33 \% / 57$ & E-NII & 57 & 289 & $\mathrm{~L}$ \\
\hline $\begin{array}{l}\text { Менеджер по } \\
\text { обучению и контролю }\end{array}$ & DI3 & 175 & $\mathrm{D}+2$ & $25 \% / 43$ & $\mathrm{D}+\mathrm{NII}$ & 50 & 254 & $\mathrm{~A} 1$ \\
\hline $\begin{array}{l}\text { Специалист } \\
\text { финансового контроля }\end{array}$ & $\mathrm{D}+\mathrm{I} 1$ & 152 & $\mathrm{D}+2$ & $25 \% / 38$ & $\mathrm{D}+\mathrm{NII}$ & 50 & 240 & A3 \\
\hline $\begin{array}{ll}\text { Специалист } & \text { по } \\
\text { поддержке бизнеса }\end{array}$ & DI2 & 152 & $\mathrm{D}+2$ & $25 \% / 38$ & DNII & 43 & 233 & $\mathrm{~A} 1$ \\
\hline $\begin{array}{l}\text { Менеджер по } \\
\text { реализации проектов }\end{array}$ & D-I2 & 132 & $\mathrm{C}+2$ & $22 \% / 29$ & D-NIII & 50 & 211 & A4 \\
\hline $\begin{array}{l}\text { Менеджер по работе с } \\
\text { заказчиками }\end{array}$ & D-I2 & 132 & $\mathrm{C}+2$ & $22 \% / 29$ & DNII & 43 & 204 & A3 \\
\hline Оператор БД & CT1 & 76 & $\mathrm{~B}+1$ & $14 \% / 10$ & BNI & 14 & 100 & $\mathrm{~A} 2$ \\
\hline $\begin{array}{l}\text { Стажер по реализации } \\
\text { проектов }\end{array}$ & C-T1 & 66 & $\mathrm{~B}+1$ & $14 \% / 9$ & BNI & 14 & 89 & $\mathrm{~A} 3$ \\
\hline
\end{tabular}


Стажер по подбору персонала

B-T1

50

$\mathrm{A}+1$

$12 \% / 6$

$\mathrm{A}+\mathrm{NI}$

10

66

A4

В таблице представлены короткие профили по каждой должности по каждому фактору с указанием параметров оценки должности внутри фактора. Все сочетания являются логичными. Также указана конечная сумма хэй-поинтов, вес, должности и ее профиль. Все должности проранжированы по убыванию их веса.
На основании таблицы с оценкой должностей выстаивается система грейдов, где указывается диапазон весов должности и номер грейда, которому она соответствует. После построения сетки грейдов строится график отклонения Нау-пунктов по грейдам, чтобы определить, верно ли была оценена должность. Рассмотрим сетку грейдов и график отклонений.

Сетка грейдов компании QWell Group Region CПб.

Таблица 3

\begin{tabular}{|c|c|c|c|c|}
\hline грейд & диапазон & min & med & max \\
\hline 8 & $1494-2069$ & 1494 & 1782 & 2069 \\
\hline 7 & $1052-1493$ & 1052 & 1273 & 1493 \\
\hline 6 & $763-1051$ & 763 & 907 & 1051 \\
\hline 5 & $550-762$ & 550 & 656 & 762 \\
\hline 4 & $401-549$ & 401 & 475 & 549 \\
\hline 3 & $271-400$ & 271 & 336 & 400 \\
\hline 2 & $151-270$ & 151 & 211 & 270 \\
\hline 1 & $45-150$ & 45 & 98 & 150 \\
\hline
\end{tabular}

\section{Относительные шаги в системе грейдов компании QWell Group Region CПб.}

\begin{tabular}{|c|c|c|c|}
\hline грейд & верт шаг & шаг min & шаг max \\
\hline 8 & $140,00 \%$ & $83,86 \%$ & $116,14 \%$ \\
\hline 7 & $140,30 \%$ & $82,67 \%$ & $117,33 \%$ \\
\hline 6 & $138,26 \%$ & $84,12 \%$ & $115,88 \%$ \\
\hline 5 & $138,11 \%$ & $83,84 \%$ & $116,16 \%$ \\
\hline 4 & $141,58 \%$ & $84,42 \%$ & $115,58 \%$ \\
\hline 3 & $159,38 \%$ & $80,77 \%$ & $119,23 \%$ \\
\hline 2 & $215,90 \%$ & $71,73 \%$ & $128,27 \%$ \\
\hline 1 & - & $46,15 \%$ & $153,85 \%$ \\
\hline
\end{tabular}

В результате, мы получили иерархию должностей, каждую отнесли к определённому грейду, диапазону, в который попадает сумма хэй-поинтов в результате оценки должности. Всего в результате получилось 8 грейдов, причем последние два имеют только одно значение внутри - это должности генерального директора и его заместителя.

Чтобы составить сетку грейдов для компании, были изначально выделены несколько групп весов должностей, значения которых не имели большой разницы между собой. Эта условная классификация была принята за основу сетки грейдов. Далее вычисляется стартовая медиана, от которой считаются горизонтальные и вертикальные шаги - относительный шаг подбирается так, чтобы все веса должностей распределялись равномерно.

Составление сетки грейдов является процессом «творческим». Это выражается в относительных шагах, указанных по вертикали шаг не является фиксированным. Горизонтальные же шаги отклонений от медианного значения одинаковые в рамках 
одного грейда - они указывают минимальное и максимальное значение диапазона суммы хэйпоинтов.

Теперь рассмотрим график отклонения Наупунктов по грейдам.

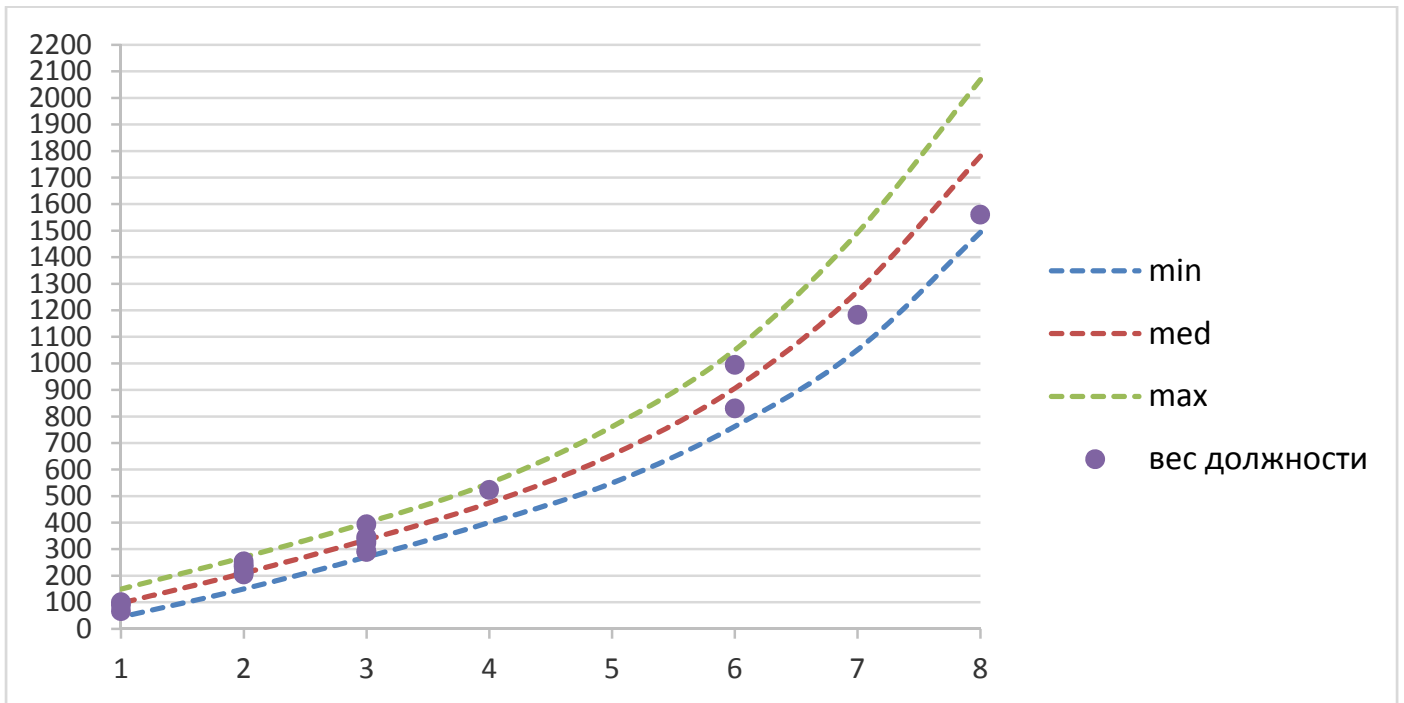

Рисунок 1 - Отклонения Нау-поинтов по грейдам компании QWell Group Region СПб.

Как видно из графика, все весы должностей попали в диапазон между минимумом и максимумом грейдов. Большинство должностей имеют вес ниже медианы, что говорит о том, что их следует переоценить в будущем. Ни одна должность не попала за рамки установленных диапазонов, следовательно - все весы определены верно.

Теперь рассмотрим аналогичную технологию определения уровня оплаты работников согласно выстроенной системе грейдов.
При построении сетки заработных плат следует учитывать факт того, что минимальное значение последующего грейда может быть не ниже значения медианы предыдущего грейда. Это является отличительной особенностью от предыдущей технологии построения сетки. В качестве стартового оклада был выбран оклад должности стажера, который составляет 17000 рублей - самой низшей в иерархии должностей.

Диапазон распределения «вилок» должностных окладов работников для каждого грейда QWell Group Region СПб, в руб.

\begin{tabular}{|c|c|c|c|}
\hline грейд & $\min$ & $\operatorname{med}$ & $\max$ \\
\hline 8 & 144613 & 192817 & 241022 \\
\hline 7 & 107121 & 142828 & 178535 \\
\hline 6 & 79349 & 105798 & 132248 \\
\hline 5 & 58777 & 78369 & 97961 \\
\hline 4 & 43538 & 58051 & 72564 \\
\hline 3 & 32251 & 43001 & 53751 \\
\hline 2 & 23889 & 31853 & 39816 \\
\hline 1 & 16500 & 23250 & 30000 \\
\hline
\end{tabular}

Таблица 6

Относительные шаги в размерах окладов работников в разработанной системе грейдов компании QWell Group Region СПб.

\begin{tabular}{|c|c|c|c|}
\hline грейд & верт шаг & шаг $\mathbf{m i n}$ & шаг max \\
\hline 8 & $135,00 \%$ & $75,00 \%$ & $125,00 \%$ \\
\hline
\end{tabular}




\begin{tabular}{|l|l|l|l|}
\hline 7 & $135,00 \%$ & $75,00 \%$ & $125,00 \%$ \\
\hline 6 & $135,00 \%$ & $75,00 \%$ & $125,00 \%$ \\
\hline 5 & $135,00 \%$ & $75,00 \%$ & $125,00 \%$ \\
\hline 4 & $135,00 \%$ & $75,00 \%$ & $125,00 \%$ \\
\hline 3 & $135,00 \%$ & $75,00 \%$ & $125,00 \%$ \\
\hline 2 & $137,00 \%$ & $75,00 \%$ & $125,00 \%$ \\
\hline 1 & - & $75,00 \%$ & $125,00 \%$ \\
\hline
\end{tabular}

Диапазоны заработных плат выстраиваются на основе рыночных тенденций в сфере оплаты труда конкретных должностей, а также на основе имеющегося фонда оплаты труда компании. Относительные шаги в сетке окладов также должны иметь равное значение по горизонтали, и могут иметь отличные значения на каждой ступени по вертикали.

При формировании данных диапазонов должностных окладов автор руководствовался минимальным должностным окладом и равными шагами как по всей вертикали, так и по горизонтали - вертикальный шаг составил $35 \%$, кроме перехода с 1 на 2 грейды, a горизонтальный $25 \%$ на всех уровнях.

Завершающим этапом процесса построения сетки должностных окладов является сравнение установленных ранее должностных окладов и получившихся согласно новой сетке грейдов. Для наглядности составляется график отклонения должностных окладов по грейдам. Рассмотрим его подробнее:

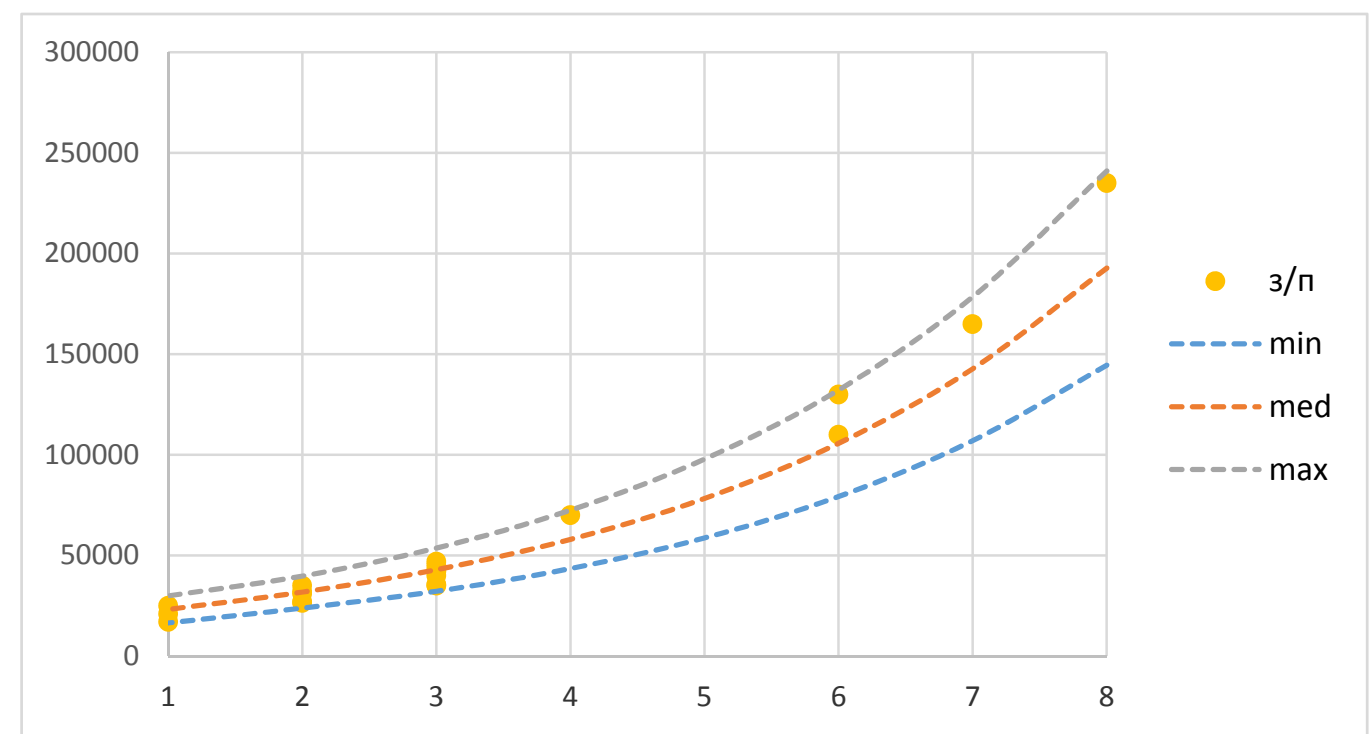

Рисунок 2 - Отклонения должностных окладов по разработанной системе грейдам компании QWell Group Region СПб.

Как видно из представленного графика, все ранее установленные должностные оклады соответствуют новой сетке грейдов. Так как внутри одного грейда (в диапазоне весов) находятся разные веса должностей, то это можно считать достаточным основанием для различия в уровнях должностных окладов в рамках одного грейда.

Таким образом, итоговая структура должностей компании QWell Group Region СПб выглядит следующим образом:

Таблица 7

Обновленная структура должностей согласно построенной системе грейдирования.

\begin{tabular}{|c|c|c|c|}
\hline Должность & Сумма хэй-поинтов & $3 / I I$ & грейд \\
\hline Директор регионального управления & 1560 & 235000 & 8 \\
\hline Заместитель руководителя & 1182 & 165000 & 7 \\
\hline Руководитель отдела по реализации проектов & 994 & 130000 & 6 \\
\hline Руководитель отдела финансового контроля & 830 & 110000 & 6 \\
\hline
\end{tabular}

ISPC European Science, 


\begin{tabular}{|l|c|c|c|}
\hline Руководитель НR-отдела & 523 & 70000 & 4 \\
\hline Ст.менеджер по подбору персонала & 393 & 45000 & 3 \\
\hline Ст. менеджер по реализации проектов & 346 & 47000 & 3 \\
\hline Ст. менеджер по обучению и контролю & 342 & 42000 & 3 \\
\hline Ст. менеджер по работе с заказчиками & 332 & 42500 & 3 \\
\hline Менеджер по подбору персонала & 323 & 40000 & 3 \\
\hline Ст. специалист по поддержке бизнеса & 291 & 35500 & 3 \\
\hline Технический специалист & 289 & 35000 & 3 \\
\hline Менеджер по обучению и контролю & 254 & 32000 & 2 \\
\hline Специалист финансового контроля & 240 & 35000 & 2 \\
\hline Специалист по поддержке бизнеса & 233 & 26500 & 2 \\
\hline Менеджер по реализации проектов & 211 & 31000 & 2 \\
\hline Менеджер по работе с заказчиками & 204 & 27000 & 2 \\
\hline Оператор БД & 100 & 25000 & 1 \\
\hline Стажер по реализации проектов & 89 & 21000 & 1 \\
\hline Стажер по подбору персонала & 66 & 17000 & 1 \\
\hline
\end{tabular}

Данная методика оценки должностей позволила адекватно оценить каждую должность в компании и сравнить ее оклад согласно ее положению в иерархии системы грейдов. Как показали расчеты, должностные оклады всех исследуемых должностей компании QWell Group Region СПб соответствуют рынку на сегодняшний момент, а также соответствуют весу должности в организации, обосновывая ее содержание.

Неверное распределение человеческих ресурсов поднимает вопрос эффективности бизнеса, его рентабельности и развития. Именно поэтому оценка должностей на основе методики компании Хэй Груп приобрела огромную популярность в деловой среде.

\section{References:}

1. Volgin NA (2014) "Reforming wage something urgent," the magazine "Man and Work" / NA Volgin. № 6,96

2. (2015) Recommendations of HayGroup Available:

http://www.haygroup.com/downloads/ru/JE Br ochure RUS.pdf (Accessed: 20.01.2015).

3. (2015) HR Magazine Publishing. official website. - Available: http://www.kdelo.ru/ (Accessed: 20.01.2015)

4. (2015) Association of Managers in Russia. official website. - Available: http://www.amr.ru (Accessed: 20.01.2015).
5. (2015) HR-Community and publications. official website. - Available: http://www.hrportal.ru (Accessed: 20.01.2015).

6. (2015) Company QWell Group. official website. - $\quad$ Available: http://qwell.biz/company.html (Accessed: 20.01.2015).

7. (2015) Available: http://compben.ru/sistemahay-group/ (Accessed: 20.01.2015). 